\title{
Research Paper: Comparing Job Satisfaction of Prehospital and Hospital Emergency Nurses in Mashhad, Iran
}

\author{
Maryam Basabr ${ }^{1}$, Hamid Reza Khankeh ${ }^{2 *}$ D, Asghar Dalvandi ${ }^{1}$, Gholamreza Ghaedamini Harouni ${ }^{3}$
}

1. Department of Nursing, University of Social Welfare and Rehabilitation Sciences, Tehran, Iran

2. Department of Clinical Science and Education, Karolinska Institute, Stockholm, Sweden.

3. Social Welfare Management Research Center, University of Social Welfare and Rehabilitation Sciences, Tehran, Iran.

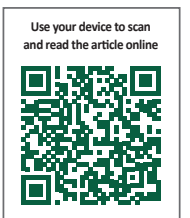

Citation: Basabr M, Khankeh HR, Dalvandi A, Ghaedamini Harouni Gh. Comparing Job Satisfaction of Prehospital and Hospital Emergency Nurses in Mashhad, Iran. Health in Emergencies and Disasters Quarterly. 2018; 4(1):15-22. http://dx.doi.org/10.32598/ hdq.4.1.15

\section{: http://dx.doi.org/10.32598/hdq.4.1.15}

\section{Keywords:}

Job satisfaction, Nurses,

Emergency service, Hospital, Prehospital emergency, Departments

\section{A B STRACT}

Background: Job satisfaction and its effective factors are important issue in productivity improvement. The main purpose of this study is to determine the job satisfaction of nurses in pre-hospital and hospital emergency rooms of Mashhad health system.

Materials and Methods: The present study was descriptive-analytic with cross-sectional design carried out on nurses working in 168 pre-hospital emergency bases and 12 emergency departments of public hospitals of Mashhad affiliated to Mashhad University of Medical Sciences in 2017. A total of 232 nurses working in pre-hospital and hospital emergency units were selected and studied. A reliable and valid questionnaire including personal and professional information was used for collecting data based on the standardized Brayfield and Ruth Job Satisfaction test. Data analysis was performed by 1-sample $t$ test, 1-way $t$ test, two Independent samples, and linear regression analysis in SPSS V. 18.

Results: A total of 232 nurses answered to questionnaires. The average quality level of job satisfaction based on Brayfield and Ruth test was $62.6 \%$ in pre-hospital emergency nurses and $62.4 \%$ in nurses of emergency hospital. It was also found that the variables of age, gender, educational level, service record, working hours, income level and marital status were significant determinants of job satisfaction, so that these variables were altogether explain about $30 \%(\mathrm{~F}=13.5, \mathrm{P}<0.001)$ of job satisfaction.

Conclusion: Based on the findings of this study, nurses' workplace is not associated with their job satisfaction. Also, job satisfaction is affected by many demographic variables, which change due to time and place and social conditions. 


\section{Introduction}

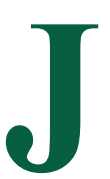

ob satisfaction is one of the effective variables of organizational performance [1]. Its high level can increase dynamism and productivity of the organization, while its low level can create problems such as job displacement, turnover, absenteeism, low motivation [2], marital conflicts and reduced efficiency and productivity in staff and organization [3]. There are many studies that assessed job satisfaction as an organizational variable. This issue can be studied at three levels [4]: 1 . Individual level, i.e. job satisfaction is actually an emotional response to a job [5]; 2. Organizational level, i.e., dissatisfied staff are more likely to be absent, resign or quite the job [6], while satisfied employees have higher levels of physical and mental health, live longer [7], and engage more in their assigned tasks [8]; and 3. Social level, i.e. job satisfaction can increase self-esteem and life satisfaction. In fact, job satisfaction affects the entire community, and employees who are satisfied with their jobs satisfy their clients, too $[9,10]$.

There are several definitions for job satisfaction. For example, Fisher and Hanna defined job satisfaction as an internal factor that is a kind of emotional adaptation to occupation and employment conditions [11]. Locke defined job satisfaction as a pleasant or positive emotional state that comes from evaluating one's job or job experience [12]. Nowadays attention to job satisfaction in health care setting has become more important [13]. Nurses, as the largest and most important members of health care organizations, have an important role in promoting health community [14]. Nurses' job satisfaction is a phenomenon that is affected by many variables [15]. Several factors such as support of managers, communication with colleagues, the nature of the job, job security, and the amount of salary and benefits have impact on the job satisfaction of nurses [16].

In Iran, the job satisfaction of nurses has been investigated in several studies, mostly indicating that their job satisfaction is at moderate level [17]. Jafar Jalal et al. [18] In their study, reported that the majority of nurses $(62 \%)$ had low job satisfaction. In the literature, almost no study was found comparing job satisfaction of prehospital and hospital emergency nurses. Prehospital and hospital emergency department, due to their particular work environment, shortage of locally trained staff [19], time limit to deal with the situation, patient's critical condition, expectations of patient's companions, openness of the workplace, and fear of incompetence in saving the lives of dying patients, have specific conditions that create stress in the employees of this sector [20-22].

Considering the bad road traffic conditions in Iran, and given that the traffic death rate in this country is much higher compared to many other countries, and also, due to the state of its medical centers and the long distance that sometimes exists between the road hospitals, emergency teams are in stressful situations at all times throughout the day [23]. Certainly, these psychological stresses can affect the job satisfaction of prehospital and hospital emergency nurses [24].

In this regard and given that the difference in job satisfaction of prehospital and hospital emergency nurses is unknown, this study attempted to investigate the job satisfaction of prehospital and hospital emergency nurses in Mashhad, Iran and compare them with each other.

\section{Materials and Methods}

This study is an analytical and cross-sectional study conducted in 2017. Study population consisted of all nurses working in prehospital emergency departments of Khorasan Razavi Province and emergency departments of public hospitals in Mashhad City. Of 26 public hospitals, only 12 hospitals took part in the study, while all prehospital emergency departments accepted to participate in our study. All nurses in these centers in three working shifts $(n=242)$ were selected as study samples (census method of sampling).

To collect data, a demographic form as well as the Persian version of Brayfield-Rothe's job satisfaction questionnaire were employed. The demographic form collected information about age, sex, level of education, marital status, type of emergency, work experience, employment status, average monthly working hours, monthly income, payment satisfaction, economic status, and insurance status. The Brayfield-Rothe's questionnaire consists of 19 items based on 5-point Likert-type scale ranging from "strongly agree" to "strongly disagree" which assesses the attitude of individuals towards their job. The score range is between 19 and 95, and the cut-off score is 57.

The validity and reliability of this questionnaire have been assessed and verified by many studies. The correlation coefficient of this test is more than $80 \%$, and its reliability score was reported as $87 \%$ by Brayfield and Rothe (1951) [25]. Reliability of its Persian version was reported as $78 \%$ by Mokhtari (1994) using split-half reli- 
ability method, and $93 \%$ by Abdollahzadeh and Karamlooei (1994) measuring Cronbach $\alpha$ coefficient [26].

While observing the ethical principles adopted by the Medical Ethics Committee of the University of Welfare and Rehabilitation Sciences, general description of the research objectives, how to fill in the questionnaire, and the confidentiality of information were given to all respondents.

The collected data were analyzed in SPSS V. 18 by performing 1-sample $t$ test, Independent $t$ test, and linear regression analysis. The data of the job satisfaction questionnaire were qualitatively analyzed and categorized at three low, moderate, and high levels.

\section{Results}

Of 242 distributed questionnaires, 232 questionnaires were completed and returned. In prehospital emergency departments where only male nurses were working, there were 115 subjects. In this group, most of the participants were in the age range of $31-40$ years $(58.3 \%)$. All of them had BS degree. Majority of them were married $(n=100,87 \%)$ with a work experience of 5 years or less $(n=42,36.5 \%)$ and under contractual employment $(n=52,45.2 \%)$. The highest monthly working hours was reported as 161-200 $\mathrm{h}(\mathrm{n}=87,75.7 \%)$ and the highest monthly income was 20 million IRR ( $n=92$, $80 \%$ ). Most of subjects in this group had moderate pay satisfaction $(n=73,63.5 \%)$ and economically were in a moderate condition $(n=83,72.2 \%)$. Moreover, most of them had health insurance $(n=111,96.5 \%)$.

In hospital emergency group, there were 117 nurses mostly female $(n=71,60.7 \%)$ with an age range of $31-$ 40 years. Most of subjects in this group were married $(n=89,76.1 \%)$, with a BS degree $(n=97,82.9 \%)$, work experience of $11-15$ years $(n=38,32.5 \%)$, and under contractual employment $(n=38,32.5 \%)$. The highest working hours in this group was 161-200 hours per month $(\mathrm{n}=66,56.4 \%)$ with a monthly income of more than 20 million IRR ( $\mathrm{n}=99,84.6 \%)$. Pay satisfaction of most of them was moderate $(n=74,63.2 \%)$, as well as their economic conditions $(n=88,75.2 \%)$ and all of them had health insurance.

One-sample t test results showed that most of hospital emergency nurses $(62.44 \%)$ and prehospital emergency departments $(62.6 \%)$ had moderate job satisfaction (Table 1). The results of the Independent $t$ test presented in Table 2 indicate no significant difference between the mean job satisfaction scores of two groups $(\mathrm{t}=0.55$, $\mathrm{P}=0.58$ ). Since the job satisfaction was the same in terms of the type of emergency, the linear regression analysis was used to investigate the effect of other demographic factors. The regression analysis results revealed that variables of gender, educational level, work experience, and income level were significant determinants of job satisfaction (Table 3).

Table 1. One-sample t test results

\begin{tabular}{|c|c|c|c|c|}
\hline \multirow{2}{*}{ Group } & \multirow{2}{*}{ Mean } & \multirow{2}{*}{ SD } & \multicolumn{2}{|c|}{ t Test } \\
\hline & & & $\mathbf{t}$ & Sig. \\
\hline Hospital emergency & 46.07 & 11.39 & 10.36 & 0.0001 \\
\hline Prehospital emergency & 45.25 & 11.29 & 11.15 & 0.0001 \\
\hline Total & 45.67 & 11.33 & 15.23 & 0.0001 \\
\hline
\end{tabular}

Table 2. The Independent $t$ test results

\begin{tabular}{ccccccc}
\hline Group & No. & Mean & & \multicolumn{2}{c}{$\begin{array}{c}\text { Levene's Test for Equality } \\
\text { of Variances }\end{array}$} & T Test for Equality of Means \\
\cline { 5 - 7 } & & & F & Sig. & t & Sig. \\
\hline $\begin{array}{c}\text { Hospital emergency } \\
\text { Prehospital emergency }\end{array}$ & 117 & 46.07 & & 0.99 & 0.55 & 0.58 \\
\hline
\end{tabular}


Table 3. Coefficients of linear regression model

\begin{tabular}{|c|c|c|c|c|c|}
\hline Model & B & Standard Error & $\beta$ & $\mathbf{t}$ & Sig. \\
\hline (Constant) & 17.68 & 5.88 & - & 3 & 0.003 \\
\hline Gender (Male) & -4.95 & 1.47 & -0.202 & -3.35 & 0.001 \\
\hline Educational level & 9.40 & 2.42 & 0.233 & 3.88 & 0.0001 \\
\hline Monthly income & 64.6 & 78.1 & 0.224 & 3.71 & 0.0001 \\
\hline Work experience & 36.2 & 0.599 & 0.238 & 94.3 & 0.0001 \\
\hline
\end{tabular}

\section{Discussion}

Based on the study findings, $62.6 \%$ of prehospital emergency nurses and $62.4 \%$ of hospital emergency nurses reported moderate job satisfaction. This is consistent with the results of Mastaneh and Mouseli and Fallahnejad and Sabagh Mollahoseiny studies [16, 27]. Mastaneh and Mouseli assessed job satisfaction and the effective demographic and job factors in nurses of teaching hospitals affiliated to Hormozgan University of Medical Sciences in Iran and found out that their job satisfaction was at moderate level.

Fallahnejad and Sabagh Mollahoseiny investigated the relationship between job satisfaction and marital satisfaction among nurses and reported that they had moderate level of job satisfaction. There is also a similar study conducted by Forouzanfar et al. examining job satisfaction of emergency nurses in hospitals affiliated to Shahid Beheshti University of Medical Silences in Iran [28]. They reported a job satisfaction of $64 \%$.

The findings of this study also revealed no significant difference between the mean score of job satisfaction of prehospital and hospital emergency groups, and the job satisfaction of nurses in both groups was at moderate level. Therefore, nurses' workplace was not related to their job satisfaction. These results are in agreement with the findings of Mastanehet and Mousel, Fallahnejad and Sabagh Mollahoseiny and Forouzanfar et al, and Lorber and Skela Savic [16, 27-29], but inconsistent with the findings of Keyvanara et al. who studied relationship between emotional labor and job satisfaction among the staff and nursing managers of the teaching hospitals affiliated to Isfahan University of Medical Sciences in Iran [30].

In their study, job satisfaction was above average. This difference may be because the type of nurses' workplace plays a role in their job satisfaction, and this satisfaction is lower in emergency wards where there are unpredictable situations, higher pressure, and limited timeframe for assessing the impact of treatments.

Our results are not in agreement with the findings of Ahmadi et al. either [31]. They examined the structural relations between job satisfaction and organization citizenship behavior among nurses working in hospitals located in Qazvin and Isfahan cities in Iran. The level of job satisfaction was reported low among the nurses. Perhaps the reason lies in the difference in studied workplace and sample size. It should be noted that job satisfaction is different depending on the social and environmental conditions such as the position of nursing profession in the community, hospital facilities, benefits, payments, salaries, and even nurses' attitudes.

The variables that were significantly related to job satisfaction in this study were gender, education, income, and work experience. Job satisfaction is likely to be affected by a variety of variables, which also changes with respect to time and place and social conditions. It seems that social, economic, and cultural conditions governing society largely determine the factors affecting the job satisfaction of nurses. In this study, there was a negative and significant relationship between gender and job satisfaction, where the job satisfaction of female nurses was lower than male ones. This is consistent with the findings of Gholami Fesharaki et al. and Zarrin Taj and Soleymani [32], while in the study of Goetz et al., women were more satisfied than men $[13,32,33]$. Probably, the relationship between job satisfaction and gender is influenced by the cultural differences and the conditions of the studied communities such as being household head, being independent, or the expectations of women from their jobs.

A positive and significant relationship was found between education level and job satisfaction, i.e. the higher the level of education of the subjects, the higher the level 
of job satisfaction. Rastgar Farghzadeh et al., Gholami Fesharaki et al. and Abbaschian et al. also found a significant association between these two variables $[5,13$, 34], but Forouzanfar et al. results are against our findings [28]. The existing facilities in the community seem to provide more job satisfaction for nurses with higher degrees. On the other hand, it can be claimed that at higher levels of education, the factors such as competence and promotion increase the job satisfaction.

The relationship between work experience and job satisfaction was positive and significant; i.e. increased work experience means higher level of job satisfaction. This is in agreement with the findings of Ommen et al. and Hosseinzadeh et al. $[35,36]$, but contrary to the findings of Baboukani et al. [37]. This maybe because in Baboukani, nurses had higher work pressure or a more difficult job [37].

Finally, in our study, it was found out that there was a positive and significant relationship between income level and job satisfaction of emergency nurses, and those with higher income, showed greater level of job satisfaction. In this regard, our study is consistent with the studies of Forouzanfar [16], Fuladvandi [17] and Marzoughi [38], but against the study of Karimi Baboukani [37]. Considering inflationary conditions prevailing in Iran's economy, in case of meeting the initial financial needs of the staff of an organization, job satisfaction can be changed into other forms such as job autonomy satisfaction or coworker relationship satisfaction.

\section{Conclusion}

Based on the findings of this study, nurses' workplace was not associated with their job satisfaction. Job satisfaction was affected by some demographic variables such as gender, education, income, and work experience. Payment satisfaction and the monthly working hours proportional to the performance, have an important role in improving the level of job satisfaction of prehospital and hospital emergency nurses.Since emergency care is more important because of its specific conditions and more vulnerable patients, it is suggested that more studies be conducted on the current situation throughout the country in order to provide valuable results for relevant authorities.

There were some limitations in conducting this study. For example, since this study examined the job satisfaction of prehospital and hospital emergency nurses in Mashhad, its results cannot be generalized to all nurses all over the country. The studied population may not be a complete picture of the population, depending on the sample size.

\section{Ethical Considerations}

\section{Compliance with ethical guidelines}

This study has been approved by the Ethics Committee of the University of Welfare and Rehabilitation Sciences (code: IR.USWR.REC.1395.293).

\section{Funding}

This paper was extracted from a Master thesis of Maryam Basabr approved by the University of Welfare and Rehabilitation Sciences.

\section{Authors contributions}

All the authors have read and approved the manuscript.

\section{Conflict of interest}

The authors declare no conflict of interest.

\section{Acknowledgments}

The authors would like to thank "115 Emergency Aid Center", emergency departments of hospitals in Khorasan Razavi Province, and all nurses participated in this study for their valuable cooperation.

\section{Reference}

[1] Kwai Fatt C, Wong Sek Khin E, Tioh Ngee H. The impact of organizational justice on employee's job satisfaction: The Malaysian companies perspectives. American Journal of Economics and Business Administration. 2010; 2(1):56-63. [DOI:10.3844/ajebasp.2010.56.63]

[2] Bahadori Khosroshahi J, Habibi Kalibar R. [The relationship between organizational agility, organizational self-esteem, morale and job satisfaction of Prinsipals (Persian)]. Journal of School Administration. 2016; 4(2):165-85.

[3] Rajabi G, Sarvestani Y, Aslani K, Khojastemehr R. [Predicators of marital satisfaction in married female nurses (Persian)]. Iran Journal of Nursing. 2013; 26(82):23-33.

[4] Neubert M, Halbesleben K. Called to commitment: An examination of relationships between spiritual calling, job satisfaction, and organizational commitment. Journal of Business Ethics. 2015; 132(4):859-72. [DOI:10.1007/s10551-014-2336-z]

[5] Rastgar Farghzadeh L, Moghaddami N, Abbasian P, Mohammadpour Z, Esmaili S, Nourizadeh R. [A survey of job satisfaction among health sector staff of Tabriz Taleghani 
Educational Hospital (Persian)]. Depiction of Health. 2016; 6(4):32-9.

[6] Hackari D, Mohammadzadeh R. [Evaluation of motivational factors and job satisfaction of nurses in relation to patient education in a number of Tabriz hospitals (Persian)]. Woman and Family Studies. 2016; 8(32):125-62.

[7] Azadi R, Eidi H. [The effects of social capital and job satisfaction on employee performance with organizational commitment mediation role (Case study, Youth and Sports Ministry) (Persian)]. Organizational Behavior Management in Sport Studies. 2016; 2(8):11-24.

[8] Hamid N, Dehghanizadeh Z. [The relationship between spirituality, organizational commitment and general health with job performance of clinical nurses (Persian)]. Quarterly Journal of Nursing Management. 2012; 1(2):20-8.

[9] Mirzaei H, Fathi L. [The study of employees'job satisfaction of East Azerbaijan province gas company (Persian)]. Sociological Studies. 2015; 5(18):137-51.

[10] Meeusen V, Van Dam K, Brown Mahoney C, Van Zundert A, Knape H. Understanding nurse anesthetists' intention to leave their job: How burnout and job satisfaction mediate the impact of personality and workplace characteristics. Health care Management Review. 2011; 36(2):155-63. [DOI:10.1097/ HMR.0b013e3181fb0f41] [PMID]

[11] Usman M, Shahzad KH, Khan KH. [Islamic Work Ethics (IWE): A review of litrature and directions for future research (Persian)]. Journal of Islamic Business and Management. 2015; 5(2):135-60. [DOI:10.12816/0026421]

[12] Ugwa E, Charity U. A Narrative review of factors affecting job satisfaction among nurses in Africa. Hospital Practices and Research. 2016; 1(3):79-82. [DOI:10.20286/hpr-010379]

[13] Gholami Fesharaki M, Akbari H, Akbari H, Mohamadian M. [Nurse job satisfaction compared with healthcare personnel: A cause cross sectional study (Persian)]. Health Research Journal. 2015; 1(1):33-41

[14] Feyzi V, Jafari RA, Farahbakhsh S, Rezaeei H. [The investigation of occupational and demographic factors effective on the quality of life of nurses and nurse aides working in teaching hospitals affiliated to Kerman University of Medical Sciences in 2014 (Persian)]. 2016; 4(3):33-40.

[15] Semachew A, Belachew T, Tesfaye T, Adinew Y. Predictors of job satisfaction among nurses working in Ethiopian public hospitals, 2014: Institution-based cross-sectional study. Human Resources for Health. 2017; 15(1):31. [DOI:10.1186/ s12960-017-0204-5] [PMID] [PMCID]

[16] Mastaneh Z, Mouseli L. [Nurses' job satisfaction and the affecting demographic and job factors in teaching hospitals affiliated to Hormozgan University of Medical Sciences, Iran (Persian)]. Journal of Kerman Medical Faculty of Management and Information. 2013; 1(1):8-17.

[17] Fuladvandi M, Amiresmail MR, Tofigh M, Fuladvandi GR, Ramezani M. [The relationship between job satisfaction and organizational citizenship behavior: A study on nurses working in intensive care units and emergency departments of hospitals affiliated with Kerman University of Medical Sciences in 2012 (Persian)]. Journal of Health and Development. 2015; 3(4):341-50.
[18] Jafar Jalal E, Joolaee S, Hajibabaee F, Bahrani N. [Evaluating the relationship between nurses' occupational satisfaction and patients' satisfaction with nursing service (Persian)]. Institute for Journalism \& Natural Resources. 2015; 10(1):25-34

[19] NooriHekmat S, Dehnavieh R, Mohammadi N, Poorhosseini S, Rezai F, Mehralhasani MH, et al. [Determining the optimum number of nursing staff Is needed in Kerman Shafa hospital emergency department (Persian)]. Two-monthly Scientific Journal of Yazd School of Public Health. 2014 13(2):140-55

[20] Mirhaghi M, Sarabian S. Relación entre el estrés percibido y rasgos de personalidad del personal de emergencia medical. Diario de Salud Mental. 2017; 18(5):265-71.

[21] Moshtagh-Eshgh Z, Aghaeinejad AA, Shahsavani A, koochaki GM, Chehregosha M, Kalantari S, et al. [An assessment of general health of operational staff of pre - hospital emergency in Golestan province (Persian)]. Journal of Health and Care. 2017; 18(4):359-67.

[22] Abrishm Kesh S, Ardalan A, Kafi Massoula M, Flaahi Khasht masjdi M. The relationship between psychological hardiness and resilience with mental health in pre-hospital emergency technicians in Guilan province. Journal of Holistic Nursing and Midwifery. 2016; 26(4):10-8.

[23] Motie MR, Kalani MR, Samadi A, Eshaghi H, Ghobadi P [Prevalence of job stressorsin male pre-hospital emergency technicians (Persian)]. The Quarterly Journal of Fundamentals of Mental Health. 2010; 12(1):420-9.

[24] Mirzabeigi Gh, healthy S, Sanjari M, Shirazi F, Heidari Sh, Maleki S. [Iranian nurses' job satisfaction (Persian)]. Journal of Hayat. 2009; 15(1):49-59.

[25] Brayfield AH., Rothe HF. An index of job satisfaction. Journal of Applied Psychology. 1951; 35(5):307-311

[26] Afshani, SA., Jahanbakhsh Ganjeh, S, Jahanbakhsh Ganjeh, S. The role of organizational commitment, social support, general health and job satisfaction in predicting burnout among the staff of Social security organization at Kohgiluyeh and Boyer Ahmad. Knowledge \& Research in Applied Psychology. 2017; 18(2):72-81.

[27] Fallahnejad T, Shahlla Sabagh Mollahoseiny F. Relationship between Job satisfaction and marital satisfaction among nurses with rotating working shift: A two year study conducted in hospitals affiliated with Alborz University of Medical Sciences. International Journal of Pharmaceutical Research \& Allied Sciences. 2016; 5(3):187-93.

[28] Forouzanfar MM, Alitaleshi H, Hashemi B, Baratloo A, Motamedi M, Majidi A, et al. [Emergency nurses 'job satisfaction and its determinants (Persian)]. Journal of Shahid Beheshti School of Nursing \& Midwifery. 2013; 23(80):11-4.

[29] Lorber M, Skela SB. Job satisfaction of nurses and identifying factors of job satisfaction in Slovenian Hospitals Croatian Medical Journal. 2012; 53(3):263-70. [DOI:10.3325/ cmj.2012.53.263] [PMID] [PMCID]

[30] Keyvanara M, Naem Isfahani M, Bahrami S, Karimi S, Azizzadeh M. [An investigation of the relationship between emotional labor and job satisfaction among the executives and nursing managers of the teaching hospitals affiliated to Isfahan University of Medical Sciences (Persian)]. Journal of Health Research in Community. 2015; 1(2):47-54. 
[31] Ahmadi AA, Mobaraki H, Yousefli M. [Structural relations between job satisfaction and organization citizenship behavior among nurses of Qazvin and Isfahan hospitals (Persian)]. The Journal of Qazvin University of Medical Sciences. 2012; 16(2):6-71.

[32] Zarrin Taj R, Soleymani M. [The study of the relationship between personality characteristics and job satisfaction among nurses in Urmia Imam Khomeini hospital (Persian)] International Journal of Humanities and Cultural Studies. 2016; 2016:1063-9.

[33] Goetz K, Musselmann B, Szecsenyi J, Joos S. The influence of workload and health behavior on job satisfaction of general practitioners. Journal of General and Family Medicine. 2013; 45(2):95-101. [PMID]

[34] Abbaschian R, Avazeh A, Rabi SiahkaliS S. [Job satisfaction and its related factors among nurses in the Public Hospitals of Zanjan University of Medical Sciences, 2010 (Persian)]. Preventive Care in Nursing \& Midwifery Journal. 2011; 1(1):17-24

[35] Ommen O, Driller E, Köhler T, Kowalski C, Ernstmann N, Neumann M, et al. The relationship between social capital in hospitals and physician job satisfaction. BMC Health Services Research. 2009; 9(1):81. [DOI:10.1186/1472-6963-9-81] [PMID] [PMCID]

[36] Hosseinzadeh M, Hosseinzadeh H, Razeghi N, Barzegar Z. [The relationship between job satisfaction and job stress and its related factors among emergency medical services personnel of Mazandaran University of Medical Sciences in 2013 (Persian)]. Journal of Neyshabur University of Medical Sciences. 2015; 3(3):55-63.

[37] Karimi Baboukani M, Keikha M, Mirzaei H, Salehiniya $\mathrm{H}$. [Factors influencing job satisfaction of nurses (Persian)]. Quarterly Journal of Sabzevar University of Medical Sciences. 2015; 22(2):55-63

[38] Marzoughi RA, Esmi A, Choopani H, Hayat AA. [Evaluation of relationship between Job satisfaction with organizational citizenship behavior of Tehran University personnels (Persian)]. Journal of Teaching and Learning. 2012; 2(2):33-56. 
